Proceedings of the 46th International School and Conference on the Physics of Semiconductors "Jaszowiec" 2017, Szczyrk

\title{
Electronic and Optical Properties of Heterostructures based on Indium Chalcogenides
}

\author{
L.Yu. Kharkhalis ${ }^{a, *}$, K.E. GluKhov ${ }^{a}$ And T.YA. BABUKA ${ }^{a, b}$ \\ ${ }^{a}$ Institute of Physics and Chemistry of Solid State, Uzhgorod National University, \\ Voloshyn St. 54, 88000 Uzhgorod, Ukraine \\ ${ }^{b}$ Institute of Physics, Faculty of Mathematics and Natural Science, Jan Długosz University in Częstochowa, \\ Al. Armii Krajowej 13/15, 42-200 Częstochowa, Poland \\ The models of the heterostructures based on the $\beta$-InSe, $\operatorname{In}_{4} \mathrm{Se}_{3}$ and $\operatorname{In}_{4} \mathrm{Te}_{3}$ crystals were proposed and the \\ first-principles study of their electronic and optical properties were presented. The band spectra, the spatial \\ distributions of the electron density and the absorption coefficients for different polarizations along crystal axes \\ for the heterostructures of the $\left(\operatorname{In}_{4} \mathrm{Se}_{3}\right)_{m} /\left(\mathrm{In}_{4} \mathrm{Te}_{3}\right)_{m}$ and $\beta$-InSe/ $\operatorname{In}_{4} \mathrm{Se}_{3}$ type were calculated. The evolution of \\ the changes in both energy spectrum and optical functions of the heterostructures in comparison with the bulk \\ crystals has been analyzed. Our calculations point out the heterostructures stability and good agreement with the \\ experimental investigations of the photosensitivity in the near and middle infrared region.
}

DOI: 10.12693/APhysPolA.132.319

PACS/topics: 31.15.A-, 31.15.ae, 71.15.Mb, 71.20.-b, 74.20.Pq, 73.21.Cd

\section{Introduction}

The indium chalcogenides keep attracting an increasing attention because of their wide applications in the optoelectronics devices development as highly sensitive dynamic and static strain sensors. In this context, the semiconductor compounds of the In-Se system and their solid solutions are used for the production of the photosensitive elements on the basis of the homo- and heterojunctions, which have been obtained by van der Waals epitaxy method and laser restructuring $[1-3]$. The formation of the $\mathrm{In}_{4} \mathrm{Se}_{3} / \mathrm{In}_{4} \mathrm{Te}_{3}$ and $\beta$-InSe $/ \mathrm{In}_{4} \mathrm{Se}_{3}$ heterostructures leads to widening of the spectral sensitivity range of the photoelements. It is established that these elements are sensitive within the range of $1.0-2.0 \mu \mathrm{m}$ and thus can be successfully used as infrared detectors and filters [4-7]. Indium selenides have also been found to be an attractive materials for solar energy conversion $[8,9]$ and excellent electrode materials for lithium ion batteries [10].

To contribute to the understanding of the spectral characteristics formation of the photosensitive devices, it is of interest to study the electronic structures and optical properties of the different heterostructures built upon $\mathrm{In}_{4} \mathrm{Se}_{3}, \mathrm{In}_{4} \mathrm{Te}_{3}$ and $\beta$-InSe crystalline semiconductors. Considered choice of the crystals is made by virtue to obtain the stable heterostructures with the perfect interfaces. In this connection it should be noted that while $\mathrm{In}_{4} \mathrm{Se}_{3}$ and $\mathrm{In}_{4} \mathrm{Te}_{3}$ orthorhombic crystals $\left(D_{2 h}^{12}\right.$ space group) are isostructural materials and lattice mismatching between constituent materials of heterostructures are small $(\approx 2 \%)$, the $\operatorname{In}_{4} \mathrm{Se}_{3}$ and $\beta$-InSe $\left(D_{6 h}^{4}\right.$ space group) layered crystals have completely different lattice types and form the strained heterostructures [11]. As it was

*corresponding author; e-mail: 1kharkhalis@gmail.com shown in our previous article [11], the strain can drastically change not only lattice parameters of connected materials but also their energy parameters. Despite experimental fabrications of the heterostructures on the base of the indium chalcogenides [1-3], theoretical investigations of electronic structure are almost absent today.

The main reason for such situation is in the complex structure of these materials thus a great number of unit cells in one period of heterostructures which contains a huge number of atoms. This factor is the main obstacle for performing ab initio investigations of such heterostructures. In this work, we propose the models of the heterostructures of $\left(\mathrm{In}_{4} \mathrm{Se}_{3}\right)_{m} /\left(\mathrm{In}_{4} \mathrm{Te}_{3}\right)_{m}$ and $\beta$ $\mathrm{InSe} / \mathrm{In}_{4} \mathrm{Se}_{3}$ type and carry out the first-principles investigations of their band energy spectra and optical properties.

\section{Modeling of the heterostructures on the base of the $\beta$-InSe, $\operatorname{In}_{4} \mathrm{Se}_{3}$ and $\operatorname{In}_{4} \mathrm{Te}_{3}$ crystals}

The presence of the materials with different conductivity and the compatibility of the crystal parameters and the similarity of the band structures are necessary conditions for the formation of the heterostructures based on the indium chalcogenides.

As it is known, the $\beta$-InSe, $\operatorname{In}_{4} \mathrm{Se}_{3}$ and $\mathrm{In}_{4} \mathrm{Te}_{3}$ indium chalcogenides occupy a special place between the strongly anisotropic materials due to a complex crystal structure. The $\mathrm{In}_{4} \mathrm{Se}_{3}$ and $\mathrm{In}_{4} \mathrm{Te}_{3}$ belong to the layered-chain materials and crystallize in orthorhombic syngony $D_{2 h}^{12}$ with nearly lattice parameters $(a=15.296 \AA, b=12.308 \AA$, $c=4.0806 \AA$ for $\operatorname{In}_{4} \mathrm{Se}_{3}$ and $a=15.619 \AA, b=12.749 \AA$, $c=4.4348$ Afor $\mathrm{In}_{4} \mathrm{Te}_{3}$ ) [12]. Their unit cell contains 28 atoms that form non-flat warped layers connected through a weak interaction. Band spectra for the $\mathrm{In}_{4} \mathrm{Se}_{3}$ and $\mathrm{In}_{4} \mathrm{Te}_{3}$ crystals are very similar. The points of the localization extremes of both the conduction and valence band are coincided and placed in the Brillouin zone center $[13,14]$. So as the $\operatorname{In}_{4} \mathrm{Se}_{3}$ compound has a larger 
band gap $\left(E_{g}^{\exp } \approx 0.65 \mathrm{eV}[15], E_{g}^{\exp } \approx 0.42 \mathrm{eV}[16]\right)$ in

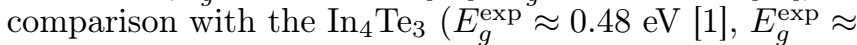
$0.29 \mathrm{eV}[16]$ ) and accordingly it is characterized by higher photosensitivity $[1,17]$. Recently in $[1,2]$ it was found that the heterostructures based on $\mathrm{In}_{4} \mathrm{Se}_{3}$ and $\mathrm{In}_{4} \mathrm{Te}_{3}$ and their solid solutions, which have been obtained by the liquid epitaxy and laser solid restructuring, are new materials for infrared technology. They are photosensitive in the spectral range $1.0-2.0 \mu \mathrm{m}$ at room temperature. The largest shift in the long-wavelength photosensitivity occurs in $n$ - $\mathrm{In}_{4} \mathrm{Se}_{3}-p$ - $\mathrm{In}_{4} \mathrm{Te}_{3}$ heterojunction [17].

Unlike to the $\mathrm{In}_{4} \mathrm{Se}_{3}$ and $\mathrm{In}_{4} \mathrm{Te}_{3}$ crystals, the $\beta$-InSe compound (the 8 of atoms per unit cell) crystallizes in a hexagonal lattice symmetry and it is described by space group $D_{6 h}^{4}(a=b=4.048 \AA, c=16.930 \AA)$ [18]. However, as it follows from the experimental studies [3], one can also create the quality heterojunctions based on $\beta$ InSe and $\mathrm{In}_{4} \mathrm{Se}_{3}$ materials with different space symmetry and lattice parameters stacked by the van der Waals contact of their surfaces. In this case the $\beta$-InSe is the frontal semiconductor for the creation of the $\beta$-InSe $/ \mathrm{In}_{4} \mathrm{Se}_{3}$ heterojunctions because it has the almost twice bigger band gap $\left(E_{g}=1.25 \mathrm{eV}\right)$ in comparison with $\mathrm{In}_{4} \mathrm{Se}_{3}$ crystal. Spectral sensitivity range of the $n-\operatorname{InSe}-p-\operatorname{In}_{4} \mathrm{Se}_{3}$ and $p$ $\mathrm{InSe}-n-\mathrm{In}_{4} \mathrm{Se}_{3}$ heterostructures is $1.0-1.8 \mu \mathrm{m}$ [3].

The crystal structures and the spatial distributions of the electron density for the $\left(\operatorname{In}_{4} \mathrm{Se}_{3}\right)_{m} /\left(\mathrm{In}_{4} \mathrm{Te}_{3}\right)_{m}(m=$ $1,2)$ and $\beta$-InSe $/ \mathrm{In}_{4} \mathrm{Se}_{3}$ heterostructures are presented in Fig. 1a and b. Both systems were geometrically optimized to obtain stable atomic configuration. Construction of the $\left(\mathrm{In}_{4} \mathrm{Se}_{3}\right)_{m} /\left(\operatorname{In}_{4} \mathrm{Te}_{3}\right)_{m}$ was carried out by such way that the Se atoms in one layer were substituted by the Te atoms unchanging the structural periodicity.

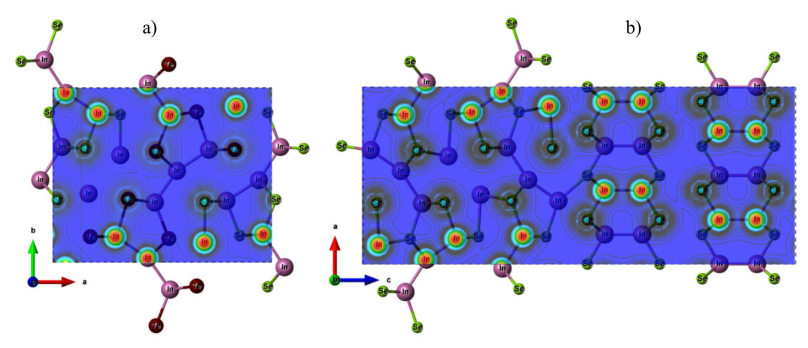

Fig. 1. The map of the electron density distribution in the unit cell of $\left(\operatorname{In}_{4} \mathrm{Se}_{3}\right)_{1} /\left(\operatorname{In}_{4} \mathrm{Te}_{3}\right)_{1}$ (a) and of $\beta$ $\mathrm{InSe} / \mathrm{In}_{4} \mathrm{Se}_{3}$ (b) heterostructures.

The symmetry lowering and the lattice parameters changes take place for both the $\left(\operatorname{In}_{4} \mathrm{Se}_{3}\right)_{1} /\left(\mathrm{In}_{4} \mathrm{Te}_{3}\right)_{1}$ and $\left(\operatorname{In}_{4} \mathrm{Se}_{3}\right)_{2} /\left(\operatorname{In}_{4} \mathrm{Te}_{3}\right)_{2}$ heterostructures. In particular, the $\left(\mathrm{In}_{4} \mathrm{Se}_{3}\right)_{1} /\left(\mathrm{In}_{4} \mathrm{Te}_{3}\right)_{1}$ heterojunction is described by $C_{2 v}^{7}$ space group $(a=15.8628 \AA, b=12.5499 \AA$, $c=4.1430 \AA)$ and more complicated $\left(\operatorname{In}_{4} \mathrm{Se}_{3}\right)_{2} /\left(\mathrm{In}_{4} \mathrm{Te}_{3}\right)_{2}$ heterostructure is characterized by the $C_{2 h}^{1}$ space group and its lattice parameters: $a=30.5920 \AA, b=12.3080 \AA$, $c=4.0810 \AA$. According to the estimation of the total energy, the considered heterostructures are stable. It also shows the spatial distribution of electron density. As it follows from our calculations, the increase of the wave function overlapping for the In atoms belonging to different layers on the heterointerface: a layer of the Se atoms and layer of the Te atoms, is obvious with the growth of the heterostructure period. The charge redistribution at the layers indicates that the formation of the heterostructures may effect on the $\operatorname{In}(\mathrm{Te})$-Se bonds.

In the article [11] it was shown that strain-balanced heterostructure $\beta$-InSe $/ \operatorname{In}_{4} \mathrm{Se}_{3}$ can be constructed of three unit cells of $\mathrm{In}_{4} \mathrm{Se}_{3}$ crystal and of twelve unit cells of $\beta$-InSe crystal. From the conditions of mechanical equilibrium of the $\beta$-InSe/ $\operatorname{In}_{4} \mathrm{Se}_{3}$ heterojunction, the strain tensor components for hexagonal and orthorhombic structures and the new parameters of the deformed $\beta$-InSe and $\mathrm{In}_{4} \mathrm{Se}_{3}$ crystals were theoretically calculated. Using the established in [11] specific orientation of the $\beta$-InSe and $\mathrm{In}_{4} \mathrm{Se}_{3}$ stacking monolayers and their matching we performed the first-principle calculations of the band spectrum and the spatial distribution of the electron density for the $\beta$-InSe $/ \mathrm{In}_{4} \mathrm{Se}_{3}$ heterostructure (using the SIESTA code [19]). As it is seen in Fig. 1b, the space charge accumulation region is observed at the heterointerfaces of $\beta$-InSe $/ \mathrm{In}_{4} \mathrm{Se}_{3}$ system.

The main result of the first-principles calculations of the band structures for the $\left(\operatorname{In}_{4} \mathrm{Se}_{3}\right)_{m} /\left(\operatorname{In}_{4} \mathrm{Te}_{3}\right)_{m}$ is the change of the bandgap. For these heterostructures, we have confirmed the appearance of the direct band gap transition in the $\Gamma$ point as well as for $\mathrm{In}_{4} \mathrm{Se}_{3}$ and $\mathrm{In}_{4} \mathrm{Te}_{3}$ bulk crystals. Unlike to the band structure of the considered heterostructures, the electronic spectrum for the $\beta$-InSe $/ \mathrm{In}_{4} \mathrm{Se}_{3}$ heterostructure is very complicated with many subbands. The electronic band structures of investigated heterostructures are very sensitive to thickness, as well the strain.

\section{Optical properties}

We carried out the investigations of the optical properties of the $\left(\operatorname{In}_{4} \mathrm{Se}_{3}\right)_{m} /\left(\operatorname{In}_{4} \mathrm{Te}_{3}\right)_{m}(m=1,2)$ and $\beta$ $\mathrm{InSe} / \mathrm{In}_{4} \mathrm{Se}_{3}$ heterostructures according to the fundamental absorption theory using density functional theory (DFT) calculation [19] and the Kramers-Kroenig relations [20]. Real and imaginary parts of the dielectric function, the absorption coefficient for different polarizations along crystal axes are determined by the expressions:

$$
\begin{aligned}
& \varepsilon_{2}(\boldsymbol{q} \rightarrow 0, \hbar \omega)= \\
& \quad \frac{2 e^{2} \pi}{\Omega \varepsilon_{0}} \sum_{\boldsymbol{k}, c, v}\left|\left\langle\Psi_{\boldsymbol{k}}^{c}|\boldsymbol{u} \cdot \boldsymbol{r}| \Psi_{\boldsymbol{k}}^{v}\right\rangle\right|^{2} \delta\left(E_{\boldsymbol{k}}^{c}-E_{\boldsymbol{k}}^{v}-\hbar \omega\right), \\
& \varepsilon_{1}(\omega)=\frac{1}{\pi} v \cdot p \int_{-\infty}^{\infty} \frac{\varepsilon_{2}\left(\omega^{\prime}\right)}{\omega^{\prime}-\omega} \mathrm{d} \omega^{\prime},
\end{aligned}
$$

where $\varepsilon_{1}=n^{2}-k^{2}, \varepsilon_{2}=2 n k$, and the absorption coefficient is $\alpha=2 k \omega / c$.

Figure $2 \mathrm{a}-\mathrm{c}$ shows the evolution of the dispersive dependences of the absorption coefficient $\alpha(\lambda)$ for different polarizations along crystal axes for the $\operatorname{In}_{4} \mathrm{Se}_{3}$ and $\mathrm{In}_{4} \mathrm{Te}_{3}$ (a) and the $\left(\mathrm{In}_{4} \mathrm{Se}_{3}\right)_{m} /\left(\operatorname{In}_{4} \mathrm{Te}_{3}\right)_{m}$ (b) and the $\beta$ InSe and $\beta$-InSe $/ \operatorname{In}_{4} \mathrm{Se}_{3}$ (c). 


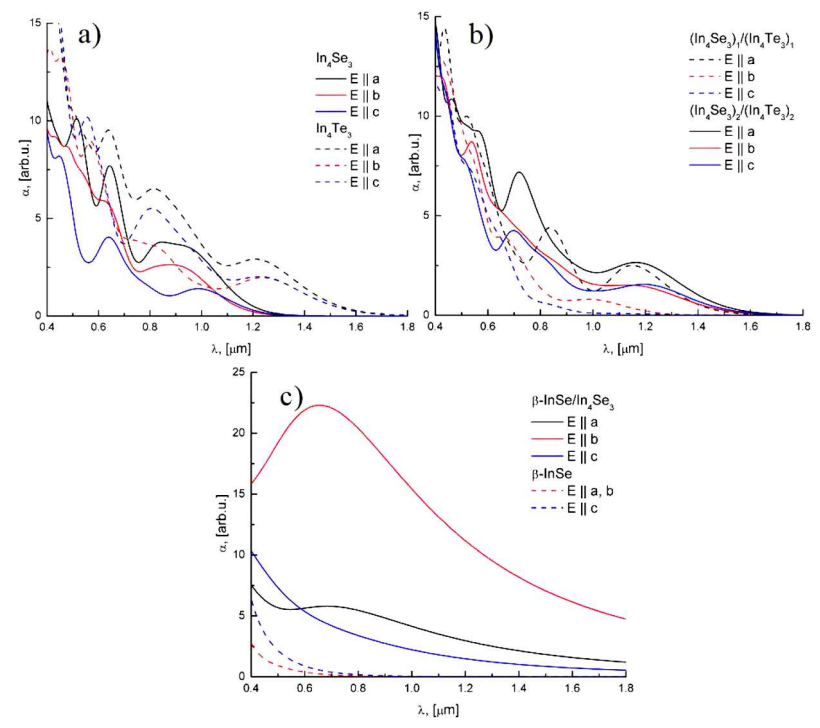

Fig. 2. Absorption coefficient dependences on the wavelength for the $\mathrm{In}_{4} \mathrm{Se}_{3}$ and $\mathrm{In}_{4} \mathrm{Te}_{3}$ crystals (a), and for $\left(\operatorname{In}_{4} \mathrm{Se}_{3}\right)_{1} /\left(\operatorname{In}_{4} \mathrm{Te}_{3}\right)_{1}$ and $\left(\operatorname{In}_{4} \mathrm{Se}_{3}\right)_{2} /\left(\operatorname{In}_{4} \mathrm{Te}_{3}\right)_{2}$ superlattices (b), and for $\beta$-InSe crystal and $(\beta$ $\mathrm{InSe}) /\left(\mathrm{In}_{4} \mathrm{Se}_{3}\right)$ heterostructure $(\mathrm{c})$.

An analysis of the absorption coefficient spectra shows the anisotropic character that is connected with the anisotropic crystal structure. Unlike to the $E \| b$ and $E \| c$ light polarizations, at the $E \| a$ light polarization the optical absorption spectra in the $\mathrm{In}_{4} \mathrm{Se}_{3}$ crystal contain the separated peaks in the $0.50-0.70 \mu \mathrm{m}$ wavelength region and the wide peak in of $0.80-1.20 \mu \mathrm{m}$ region, while for the $\mathrm{In}_{4} \mathrm{Te}_{3}$ crystal the wide peak is shifted to the region of $1.10-1.60 \mu \mathrm{m}$. With the $\left(\mathrm{In}_{4} \mathrm{Se}_{3}\right)_{m} /\left(\mathrm{In}_{4} \mathrm{Te}_{3}\right)_{m}$ heterostructure construction the spectral region widening as well as the shift of absorption spectra into longwave region take place. The essential change of the absorption coefficients spectra is observed for the $\beta$-InSe $/ \mathrm{In}_{4} \mathrm{Se}_{3}$ heterostructure. Especially, the peak intensity increases in comparison with one for the bulk crystals and the $\left(\operatorname{In}_{4} \mathrm{Se}_{3}\right)_{m} /\left(\operatorname{In}_{4} \mathrm{Te}_{3}\right)_{m}$ heterostructures. The shift of the optical absorption coefficient into the longwave region is found for $\beta$-InSe/ $\mathrm{In}_{4} \mathrm{Se}_{3}$ heterostructure, too. This factor can be related to specific stacked structure.

\section{Conclusions}

We have performed the first-principle calculations of the band spectra, the spatial distributions of the electron density and the absorption coefficients for different polarizations along crystal axes for the $\mathrm{In}_{4} \mathrm{Se}_{3}$ and $\mathrm{In}_{4} \mathrm{Te}_{3}$ layered orthorhombic crystals and the $\left(\mathrm{In}_{4} \mathrm{Se}_{3}\right)_{m} /\left(\mathrm{In}_{4} \mathrm{Te}_{3}\right)_{m}$ and $\beta$-InSe $/ \mathrm{In}_{4} \mathrm{Se}_{3}$ heterostructures. The evolution of the changes in the symmetry and both energy spectrum and optical functions of the heterostructures in comparison with the bulk crystals had been analyzed. It is shown that the widening of the spectral sensitivity range takes place with the increase of the heterostructures thickness. The strain-induced electronic structure changes in the $\beta$-InSe/ $\mathrm{In}_{4} \mathrm{Se}_{3}$ heterostructures have been analyzed well.
Our calculations point out the possibility of the forming of the stable heterostructures on the base of the indium chalcogenides and will guide the design of future applications of this type of heterostructures in the near and middle infrared region spectra.

\section{Acknowledgments}

This work was partially supported by research project No. 2016/21/N/ST3/00461 from the Polish National Science Centre.

\section{References}

[1] G.I. Vorobets, V.V. Strebezhev, V.M. Tkach, O.I. Vorobets, V.M. Strebezhev, J. Educat. Techn. Sci. 2, 5 (2015).

[2] T.A. Melnychuk, V.M. Strebegev, G.I. Vorobets, Appl. Surf. Sci. 254, 1002 (2007).

[3] Z.D. Kovalyuk, V.M. Katerynchuk, B.V. Kushnir, M.V. Tovarnytskyi, J. Surf. Phys. Eng. 1, 242 (2016).

[4] B.M. Gritsyuk, O.V. Galochkin, A.I. Rarenko, V.N. Strebezhev, Proc. SPIE 5065, 139 (2003).

[5] I.K. Obedzynskyi, B.N. Gritsyuk, V.V. Strebegev, V.N. Strebegev, I.M. Yuriychuk, East.-Europ. J. Enterpr. Technol. 6, 44 (2012).

[6] V.V. Strebegev, V.N. Strebegev, S.V. Nichyi, I.M. Yuriychuk, East.-Europ. J. Enterpr. Technol. 66, 113 (2013).

[7] B.M. Gritsyuk, T.S. Moschkova, A.D. Ogorodnik, I.M. Rarenko, T.A. Volyanska, J. Appl. Spectrosc. 66, 577 (1999).

[8] A. Segura, J.P. Guesdon, J.M. Besson, A. Chevy, Rev. Phys. Appl. (Paris) 14, 253 (1979).

[9] A. Segura, J.P. Guesdon, J.M. Besson, A. Chevy, J. Appl. Phys. 54, 876 (1983).

[10] Seung Mi Oh, Eunsil Lee, Kanyapom Adpapang, Sharad B. Patil, Mi Jin Park, Young Soo Lim, Kyu Hyoung Lee, Jong-Young Kim, Seong-Ju Hwang, Electrochim. Acta 170, 48 (2015).

[11] T.Ya. Babuka, K.E. Glukhov, Superlatt. Microstruct. 100, 448 (2016).

[12] J.H.C. Hogg, H.H. Sutherland, D.J. Williams, J. Chem. Soc. D Chem. Commun. 23, 1568 (1971).

[13] Xingfu Li, Bin Xu, Gongqi Yu, Li Xue, Lin Yi, J. Appl. Phys. 113, 203502 (2013).

[14] M. Sznajder, K.Z. Rushchanskii, L.Yu. Kharkhalis, D.M. Bercha, Phys. Status Solidi B 243, 592 (2006).

[15] V.P. Savchin, Fiz. Tekh. Poluprovodn. 15, 1430 (1981).

[16] Xun Shi, Jung Y. Cho, James R. Salvador, Jihui Yang Hsin Wang, Appl. Phys. Lett. 96, 162108 (2010).

[17] B.N. Gritsyuk, V.N. Strebegev, I.M. Yuriychuk, Naukovij visnik Cerněvec'kogo Universitetu. Fizika, elektronika 2, 34 (2012).

[18] L.I. Man, R.M. Imamov, S.A. Semiletov, Kristallografia 21, 628 (1979).

[19] J.M. Soler, E. Artacho, J.D. Gale, A. Garcia, J. Junquera, P. Ordejon, D. Sanchez-Portal, J. Phys. Condens. Matter 14, 2745 (2002).

[20] E.D. Palik, Handbook of Optical Constants of Solids, Academic Press, Orlando 1985. 